\title{
SIMPLE AND FAST ANALYTICAL METHOD FOR THE EVALUATION OF THE ENCAPSULATION AND RELEASE PROFILE OF DOXORUBICIN FROM DRUG DELIVERY SYSTEMS
}

\author{
IULIA RUS ${ }^{1}$, MIHAELA TERTIȘ ${ }^{1}$, VIOLETA PAŞCALĂU ${ }^{2}$, CODRUȚA PAVEL ${ }^{2}$, BIANCA \\ MELEAN $^{1}$, MARIA SUCIU ${ }^{3,4}$, CRISTIAN MOLDOVAN ${ }^{5}$, TAMARA TOPALĂ ${ }^{6}$, CĂTĂLIN \\ POPA $^{2}$, ROBERT SĂNDULESCU ${ }^{1}$, CECILIA CRISTEA ${ }^{1 *}$ \\ IDepartment of Analytical Chemistry, Faculty of Pharmacy, "Iuliu Haţieganu” University of Medicine and Pharmacy, \\ 400349, Cluj-Napoca, Romania \\ ${ }^{2}$ Department of Materials Science and Engineering, Technical University of Cluj-Napoca, 400641, Cluj-Napoca, Romania \\ ${ }^{3}$ National Institute for Research and Development of Isotopic and Molecular Technologies, 400293, Cluj-Napoca, Romania \\ ${ }^{4}$ Biology and Geology Faculty, "Babeș-Bolyai" University, 400006, Cluj-Napoca, Romania \\ ${ }^{5}$ MedFuture Research Center for Advanced Medicine “Iuliu Haţieganu” University of Medicine and Pharmacy, 400349, \\ Cluj-Napoca, Romania \\ ${ }^{6}$ Department of Inorganic Chemistry, Faculty of Pharmacy, "Iuliu Haţieganu” University of Medicine and Pharmacy, \\ 400010, Cluj-Napoca, Romania
}

*corresponding author: ccristea@umfcluj.ro

Manuscript received: December 2020

\begin{abstract}
Drug delivery systems are the most researched pharmaceutical formulation, representing promising tools in the treatment of cancer. Doxorubicin is an anti-tumour drug, widely used in malignant diseases, but with serious adverse effects. The aim of this study was to develop an analytical strategy for the evaluation of the encapsulation and release of this drug from delivery systems. The electrochemical oxidation process of doxorubicin has been studied using pencil graphite electrode by a fully optimized differential pulse voltammetry procedure. This electro-analytical method was successfully applied for the evaluation of the encapsulation and release profile of doxorubicin from biocompatible and biodegradable microcapsules, UV-Vis spectroscopy being applied as control method.
\end{abstract}

\section{Rezumat}

Sistemele de transport la țintă sunt cele mai cercetate formulări farmaceutice fiind promițătoare pentru tratamentul cancerului. Doxorubicina este un antitumoral utilizat pe scară largă în afecțiunile maligne, dar care produce reacții adverse serioase. Scopul acestui studiu a fost de a dezvolta o strategie analitică pentru evaluarea încapsulării și eliberării acestui medicament din sisteme de transport la țintă. Procesul de oxidare electrochimică a doxorubicinei a fost studiat utilizând mina de creion și o procedură optimizată de voltametrie puls diferențială. Această metodă electro-analitică a fost aplicată cu succes pentru evaluarea procesului de încărcare și eliberare a doxorubicinei din microcapsule biocompatibile, spectroscopia UV-Vis fiind utilizată ca metodă de control.

Keywords: doxorubicin, electrochemical detection, targeted drug release

\section{Introduction}

Doxorubicin (Dox) is the most common anti-tumour drug from the class of anthracyclines, together with daunorubicin, epirubicin, idarubicin and valrubicin, all these molecules being structurally related. Dox manifests its antineoplastic activity through a double mechanism of action. Firstly, the drug intercalates between the pairs of nitrogenous bases from DNA structure, preventing DNA replication, and secondly, Dox works as a topoisomerase II inhibitor, stabilizing the DNA-enzyme complex and preventing thus relegation of DNA double helix, the second reaction being catalysed by topoisomerase II. Moreover, free radicals are generated by Dox and they produce damage of the cell membranes, DNA and proteins, leading to apoptosis $[7,19]$.

Dox has proved its efficacy in various malignancies, such as lymphoblastic and acute myeloblastic leukaemia, Hodgkin's disease, malignant lymphoma, soft tissue and bone sarcoma, neuroblastoma, breast, ovarian, thyroid and gastric carcinoma. Even though this drug is indicated in the treatment of numerous diseases and it has a relatively low cost, its side effects are major drawbacks. It has been shown that Dox produces myocardial damage, the risk of cardiomyopathy being proportional to the exposure and increased by concomitant cardiotoxic medication. Another unwanted effect of this drug is the hematologic toxicity manifested through severe myelosuppression, resulting in anaemia, thrombocytopaenia, neutropenia and most important leukopenia. 
On this background, severe infections can occur, with possibility of developing septic shock that could bring death. Local tissue injury and necrosis can also happen because of the extravasation of Dox [19]. In 1995, FDA approved the first drug delivery system containing Dox, which was a PEGylated liposome for human use in metastatic ovarian cancer and in Kaposi sarcoma related to acquired immune deficiency syndrome. This pharmaceutical formula brought the advantage of diminishing side effects severity. After this, other liposomal doxorubicin products were developed and approved, including Thermodox ${ }^{\circledR}$, whose release is heat dependent [24]. Thus, in the last decades, an impressive number of various drug delivery systems encapsulating Dox were described, most of them being still at the stage of pre-clinical research. Among them, the following should be mentioned: polymeric nanoparticles having in composition chitosan, pullulan or arabinogalactan, micelles, exosomes, magnetic carriers and DNA intercalated Dox nanoparticles or gold nanoparticles [1, 36]. Regarding the release mechanism and the targeted transport, there are also different types of drug delivery systems among which could be reminded the ones with $\mathrm{pH}$ dependent or thermal release, with surface ligands for specific receptors of tutor cells or the ones guided at the tumour site using a magnetic field $[16,32,34,36]$.

According to the European Pharmacopoeia (EP), the identification of Dox is performed by using infrared absorption spectrophotometry, while the quantitative analysis requires a HPLC-UV method [9]. Therefore, in the majority of studies, HPLC-UV, HPLC-MS or $\mathrm{UV}-\mathrm{V}$ is spectrophotometry are used to evaluate the encapsulation efficiency and the release profile of Dox from drug delivery systems. Even though the selectivity of the electrochemical method is not as good as the one offered by HPLC hyphenated techniques, considering the purpose of the study, the nature of the samples analysed, this method brings other important advantages, such as high sensitivity and efficiency, coupled with low cost and simplicity. An electrochemical method for the evaluation of the encapsulation and release of Dox from drug delivery systems was developed and, for the first time, reported within the present study, using Differential Pulse Voltammetry (DPV) on pencil graphite electrode (PGE). Core-shell microcapsules (MCPs) based on bovine serum albumin (BSA), hyaluronic acid (HA) and chitosan (Chi) were used for the evaluation of the encapsulation and release processes [21]. The results obtained using the new electrochemical method was compared with the ones obtained by using the UV-Vis detection method.

\section{Materials and Methods}

Doxorubicin hydrochloride $>95.0 \%$ bought from Tokyo Chemical Industry Company was used as loading anti-tumour medicine on polymeric MCPs which were prepared based on a protocol described in another study $[21,30]$. Details regarding the synthesis and characterization of MCPs can be found there [21]. Sodium acetate, sodium citrate, sodium phosphate dibasic, sodium phosphate monobasic, hydrochloric acid, potassium chloride and dimethylsulfoxide (DMSO) bought from Sigma Aldrich were used to prepare the encapsulation media. Also, sulphuric acid and acetone acquired from Sigma Aldrich were used in the cleaning process of the electrodes which was afterwards checked by testing the electrodes in a $\left[\mathrm{Fe}(\mathrm{CN})_{6}\right]^{3-/ 4-}$ solution prepared from potassium hexacyanoferrite/hexacyanoferrate bought from Merck in $0.1 \mathrm{M}$ potassium chloride. For the interference studies, gemcitabine hydrochloride $>98 \%$ achieved from Sigma Aldrich and simvastatin provided by Biocon Limited, India were used.

The electrochemical behaviour of Dox was investigated on different types of screen-printed electrodes (SPEs) produced by DropSens Metrohm, Spain, as well as on PGE bought from Rotring ${ }^{\circledR}$, Germany. Therefore, SPEs of $\mathrm{Au}, \mathrm{Pt}$, graphite and graphite modified with single-walled carbon nanotubes (SWCNT) or gold nanoparticles (AuNPs), B hardness and $1 \mathrm{~mm}$ diameter PGE and HB hardness $0.5 \mathrm{~mm}, 0.75 \mathrm{~mm}, 1 \mathrm{~mm}$ PGE were used to evaluate the influence of the electrode material on the detection of Dox. The measurements regarding the MCPs loading and the release process were performed on PGE, HB hardness and $1 \mathrm{~mm}$ diameter.

UV-Vis absorption spectroscopy tests were performed using a SPECORD 250 PLUS spectrophotometer operated with WinAspect specific software. After the appropriate absorption spectra were drawn, the specific wavelengths were chosen for all solvents used. Thus, the maximum absorbance for Dox was found at a wavelength of $484 \mathrm{~nm}$ in DMSO, at $255 \mathrm{~nm}$ in acetate buffer solution of $\mathrm{pH} 4.5$ and in phosphate buffer solution of $\mathrm{pH} 6.8$, at $234 \mathrm{~nm}$ in citrate buffer solution of $\mathrm{pH}$ 5. Dox solutions of different concentrations were prepared and their absorbance was measured. A calibration curve was drawn in each situation in order to find the correlation between the absorbance and Dox concentration. The obtained equations were further used to determine the Dox concentration in the loading and release samples. The results were compared with the ones obtained with the optimized DPV method, after scanning the potential at the electrode between $0.1 \mathrm{~V}$ and $0.9 \mathrm{~V}$, with a scan rate of $0.005 \mathrm{~V} / \mathrm{s}$, using a multi-channel potentiostat/ galvanostat Autolab MAC80100 (Metrohm, The Netherlands). The same equipment was used for the electrochemical cleaning of the PGE by cyclic voltammetry $(\mathrm{CV})$. This cleaning procedure involved 5 cycles between $1.4 \mathrm{~V}$ and $-1.0 \mathrm{~V}$, with a scan rate of $0.1 \mathrm{~V} / \mathrm{s}$, in $0.5 \mathrm{M}$ sulphuric acid. Just before the $\mathrm{CV}$ cleaning, the PGE were immersed in acetone for 
1 minute in order to remove the organic impurities that may be present on the surface.

The $\mathrm{pH}$ of all buffer solution was established using a pH-meter HI208 (Hanna Instruments).

The characterization of the MCPs and Dox encapsulated MCPs (MCPs-Dox) was achieved with FTIR (Fourier transform infrared) spectroscopy, using an ATR FTIR spectrometer (Jasco FT-IR 4100) equipped with a ZnSe ATR crystal. The spectra were collected using the attenuated total reflection technique in the 4000 $500 \mathrm{~cm}^{-1}$ spectral range with a resolution of $4 \mathrm{~cm}^{-1}$ and averaged over 32 scans, and Jasco Manager 2 software for the interpretation of the results, as well as with scanning electron microscopy (SEM), using a Hitachi SU8230 device, at $30 \mathrm{kV}, 10 \mu \mathrm{A}$, and $8 \mathrm{~mm}$ working distance. The microcapsules were imaged under an Olympus FLUOVIEW FV1200 laser scanning fluorescence confocal microscope. Image acquisition was performed using the UAPON100xOTIRF (1.49 NA) objective. The images were obtained using the channel mode: one channel for the visualization of Dox at $488 \mathrm{~nm}$ excitation and one for Differential interference contrast (DIC) microscopy. Images were processed using ImageJ.

Encapsulation process

A quantity of approximately $0.3 \mathrm{~g}$ of MCPs was weighted in three Eppendorf tubes using an analytical microbalance. Solutions of $2 \mathrm{mg} / \mathrm{mL}, 5 \mathrm{mg} / \mathrm{mL}$ and $10 \mathrm{mg} / \mathrm{mL}$ of Dox in DMSO were prepared and 2.6 $\mathrm{mL}$ of each were poured over the weighted microcapsules. The samples were mixed at room temperature for 24 hours using an Invitrogen Hula mixer in the following condition: orbital movement of $3 \mathrm{rpm}$ for $90 \mathrm{~s}$, reciprocal movement of $1^{\circ}$ for $5 \mathrm{~s}$ and vibration movement of $1^{0}$ for $1 \mathrm{~s}$.

The encapsulation was made using the same experimental parameters and conditions also from Dox solutions prepared in three types of aqueous buffers. Thus, approximately $0.5 \mathrm{~g}$ of MCPs were weighted in three tubes over which were poured the following solutions: $2 \mathrm{mg} / \mathrm{mL}$ Dox in $0.1 \mathrm{M}$ acetate buffer solution of $\mathrm{pH} 4.5,2 \mathrm{mg} / \mathrm{mL}$ Dox in $0.002 \mathrm{M}$ citrate buffer solution of $\mathrm{pH} 5$ and $2 \mathrm{mg} / \mathrm{mL}$ Dox in $0.002 \mathrm{M}$ citrate buffer solution of $\mathrm{pH} 5.5$.

After $24 \mathrm{~h}, 500 \mu \mathrm{L}$ were sampled from each tube and diluted to $4 \mathrm{~mL}$ with the same solvent. The concentration of Dox was determined using the appropriate calibration curve. Considering the dilution and the initial concentration of the sample, the quantity of Dox encapsulated was calculated. The encapsulation efficiency $(E E(\%))$ and loading capacity $(L C(\%))$ were also calculated, using the following formulas [22]:

$$
\begin{gathered}
E E=\left(\left(V \mathrm{x} C_{i}-V \mathrm{x} C_{f}\right) /\left(V \mathrm{x} C_{i}\right) \times 100\right)(\%) ; \\
L C=\left(\left(V \times C_{\mathrm{i}}-V \times C_{f}\right) / m_{M C P s-D o x} \times 100\right)(\%) ;
\end{gathered}
$$

where $V$ is the volume of the release medium, $C_{i}$ is the initial concentration of Dox, $C_{f}$ is the final concentration of Dox (after encapsulation) and $m_{M C P s-D o x}$ is the weight of the loaded MCPs.

Release conditions

A quantity of approximately $0.15 \mathrm{~g}$ of MCPs-Dox was weighted in three dialysis bags (MWCO: $3.5 \mathrm{kDa}$, ThermoFisher Scientific, USA) using an analytical microbalance, and the bags were introduced in three glass vials. Different buffer solutions were prepared: $0.1 \mathrm{M}$ acetate buffer solution of $\mathrm{pH} 4.5,0.002 \mathrm{M}$ citrate buffer solution of $\mathrm{pH} 5$ and $0.1 \mathrm{M}$ phosphate buffer solution of $\mathrm{pH}$ 6.8. $1.5 \mathrm{~mL}$ of each buffer solution was poured over the loaded MCPs. The tubes were closed and stirred at constant temperature of $37^{\circ} \mathrm{C}$ with an Eppendorf Termomixer ${ }^{\circledR} \mathrm{C}$.

From each tube, $500 \mu \mathrm{L}$ were sampled after each 15 minutes in the first hour, after each hour in the first 6 hours and after each 24 hours in the next three days. The samples were diluted to $4 \mathrm{~mL}$ with the specific buffer solution and Dox concentration was determined using the optimized DPV procedure and the results were compared with the ones obtained with the UV-Vis spectrophotometric technique. The precision of the results obtained with both mentioned above methods were statistically analysed with the Student's t-test, which indicates whether there are significant differences between these two methods at a confidence level of $95 \%$.

Considering the dilutions made at each time of sampling, the concentration of Dox at each time was calculated. Using the following equations, the cumulative mass and the cumulative release of Dox (\%) were also determined:

$$
\begin{gathered}
m_{n}=\left(C_{n} \mathrm{x} V\right)+V_{s}\left(C_{1}+C_{2}+C_{3}+\ldots+C_{n-1}\right) ; \\
C r_{n}=\left(m_{n} / m_{\text {load }} \mathrm{x} 100\right),
\end{gathered}
$$

where $m_{n}$ is cumulative mass at a specific time $(n)$, $C r_{n}$ is the concentration of Dox from the release medium at that time $(n), V$ is the volume of the release medium, $V_{s}$ is the volume sampled at each time tested, $C_{1}, C_{2} \ldots C_{n-1}$ are the concentrations of Dox at all the other times tested before, and $m_{\text {load }}$ is the mass of Dox loaded in the quantity of MCPs used for this study. All the release experiments were performed in triplicate and all samples were analysed 3 times with each of the methods used in this study.

\section{Results and Discussion}

Electrochemical characterization of doxorubicin $\mathrm{CV}$ tests of Dox in $0.1 \mathrm{M}$ acetate buffer solution of pH 3.2 were operated on different types of SPE: Au, Pt or graphite-based, graphite modified with SWCNT and with AuNPs, respectively. In the case of $\mathrm{Au}$ and Pt electrodes, several signals of oxidation and reduction were observed also in the absence of Dox. These signals can be related with the redox processes that can occur in acidic aqueous solution at the surface of this type of electrodes [29]. Thus, the next studies were done 
using graphite-based electrodes, an electrochemically inactive material. It was observed that the best results regarding the peak intensity were obtained on graphite SPE and graphite SPE modified with SWCNT (data not shown). Considering the high costs of using SPE for encapsulation-release tests, an alternative more accessible, versatile and cheaper are PGEs, due to their small dimensions that could allow a flow analysis and a semi-automatic method for drug release investigation. Therefore, different types of pencil graphite were tested, including HB and B hardness, as well as 0.5 $\mathrm{mm}, 0.75 \mathrm{~mm}$ and $1 \mathrm{~mm}$ diameter, all of them having $1 \mathrm{~cm}$ length PGE isolated with polymeric polish $\left(0.605 \mathrm{~cm}^{2}\right)$. The results showed that the signal is higher with the percent of graphite (higher for B than for $\mathrm{HB}$ ) and with the increasing of the diameter and

consequently of the electrochemically active surface. In all cases, the signal had a better intensity than the one obtained on a glassy carbon electrode with a stable active surface of $0.126 \mathrm{~cm}^{2}$, in the presence of $10 \mathrm{mM}[\mathrm{Fe}(\mathrm{CN}) 6]^{4-/ 3-}$. However, PGE with higher percent of graphite are more fragile and easy to break, thus the PGE chosen to work with were HB hardness and $1 \mathrm{~mm}$ diameter.

An optimization of the cleaning process of PGE was performed. For this purpose, the analytical signals obtained on the potential domain of interest were compared before cleaning the PGE, after cleaning through immersion in acetone, after using $\mathrm{CV}$ and after both immersion in acetone and CV. The last method was proved to be the most efficient, thus this type of cleaning was used in further studies (Figure 1(A)).
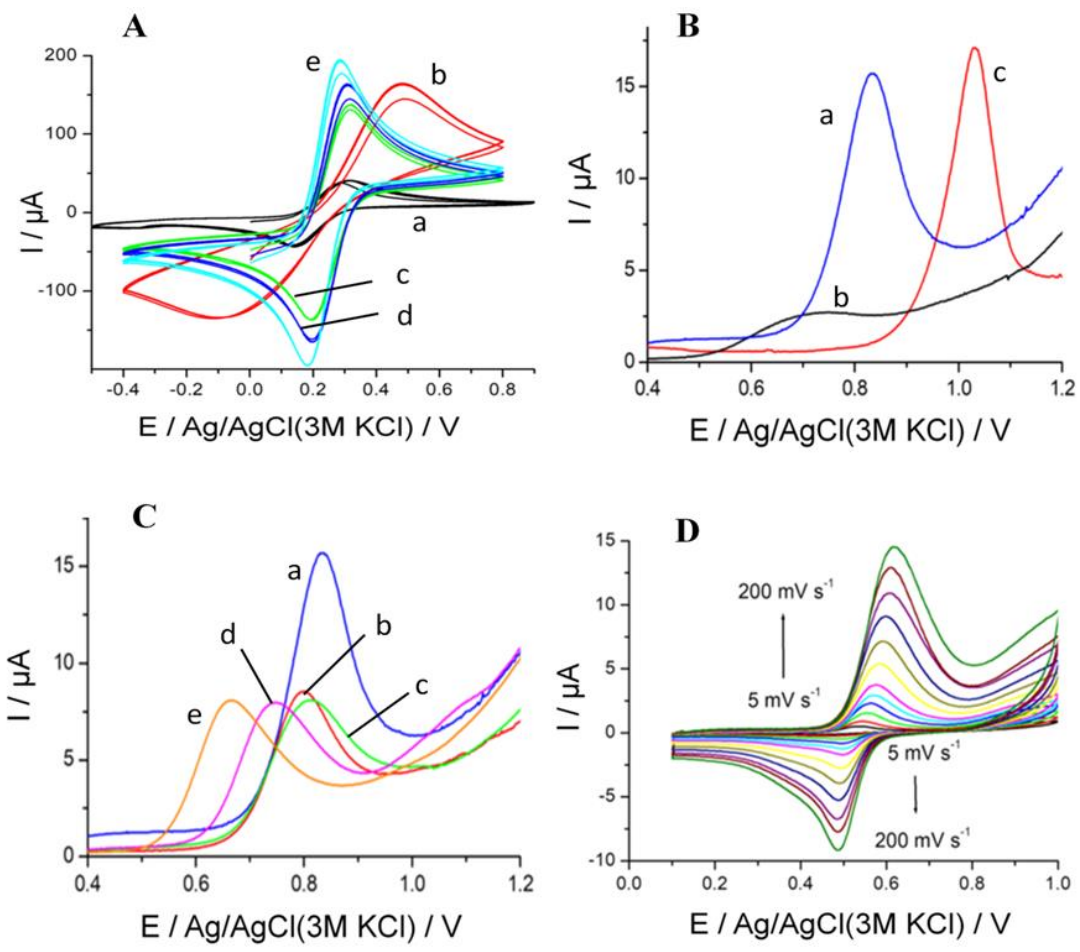

Figure 1.

(A) CVs of a $\left[\mathrm{Fe}(\mathrm{CN})_{6}\right]^{3-/ 4-}$ solution for: clean GCE (d = $\left.3 \mathrm{~mm}, \mathrm{BASi}\right)(\mathrm{a}), 1 \mathrm{~cm}$ PGE HB (d = $\left.1 \mathrm{~mm}\right)$ unclean (b), $1 \mathrm{~cm}$ PGE HB after acetone cleaning (c), $1 \mathrm{~cm}$ PGE HB after electrochemical cleaning with $0.5 \mathrm{M} \mathrm{H}_{2} \mathrm{SO}_{4}, 5$ cycles (d), $1 \mathrm{~cm}$ PGE HB after 1 min acetone and electrochemical cleaning with $0.5 \mathrm{M} \mathrm{H}_{2} \mathrm{SO}_{4}, 5$ cycles (e). (B) LSVs of $10 \mu \mathrm{g} / \mathrm{mL}$ Dox in different electrolyte solutions (0.1 M acetate buffer pH 3.2 (a), $0.002 \mathrm{M}$ citrate buffer pH 6.8 (b), $0.1 \mathrm{M}$ sulphuric acid (c), using $1 \mathrm{~cm}$ PGE HB; (C) LSVs of $10 \mu \mathrm{g} / \mathrm{mL}$ Dox in acetate buffer solutions of different pH (3.2 (a), 4.5 (b), 5 (c), 5.5 (d) and 6.9 (e), using $1 \mathrm{~cm}$ PGE HB. (D) CVs of $10 \mu \mathrm{g} / \mathrm{mL}$ Dox in $0.1 \mathrm{M}$ acetate buffer solution of $\mathrm{pH} 5.5$ using $1 \mathrm{~cm}$ PGE HB and different scan rate $(5-200 \mathrm{mV} / \mathrm{s})$.

Electrolytes of different $\mathrm{pH}$ values were also tested by using Linear Sweep Voltammetry (LSV). For this purpose, $0.1 \mathrm{M}$ acetate buffer of $\mathrm{pH} 3.2,4.5,5,5.5$ and $6.8 ; 0.002 \mathrm{M}$ citrate buffer of $\mathrm{pH} 6.8$; and 0.1 $\mathrm{M}$ sulphuric acid were used. As it can be observed in Figure 1(C), in the oxidation range of potential, an oxidation peak is well represented for Dox in acetate buffer solutions, due to the oxidation of the hydroquinone moiety in quinone, followed by the reduction of quinone moiety in its aglycone, produced at the electrode surface via two electrons and two proton processes $[10,12]$. With the increase of $\mathrm{pH}$, the analytical signal corresponding to Dox oxidation is shifted towards lower values of potential and its intensity is decreasing. These results indicated that the protons are involved in the electrode reaction processes related with Dox. At $\mathrm{pH} 6.8$, in citrate buffer solution, this signal was 
FARMACIA, 2021, Vol. 69, 4

significantly smaller, probably due to the fact that Dox is easily degraded in solutions of more basic $\mathrm{pH}$ as it was already reported in other studies (Figure 1(B)) [2, 13]. Considering this, solutions of more basic $\mathrm{pH}$ values were avoided and $0.1 \mathrm{M}$ acetate buffer solutions of $\mathrm{pH}$ less than 6 were chosen for further experiments. According to the experimental results, the proposed mechanism for electrochemical transformation of Dox involved also two electrons, this being consistent with the known electrochemical oxidation reported in other studies for Dox [10, 12].

The scan rate brings useful information about the mechanism of the electrochemical process, especially from kinetic point of view. The influence of scan rate values between 0.005 and $0.200 \mathrm{~V} / \mathrm{s}$ on $\mathrm{I}_{\mathrm{p}}$ was studied and the results are presented in Figure 1(D). In Figure 1(D) it can be observed that the reduction peak is shifted toward more negative values of potential with the increasing of scan rate, while the oxidation peak is shifted toward more positive values of potential. Even though this fact usually indicates an irreversibility of the process, in this case, the peak-to-peak potential is still in the range of a reversible process. The shifting of the redox potentials suggest also that the electrochemical process is controlled by the adsorption of the molecules at the electrode's surface.
The analytical parameters for the electrochemical detection of Dox

The variation of the intensity of the oxidation current (I) with Dox concentration was graphically represented based on DPV graphs achieved using PGE (Figure 2 ), obtaining the equation of the calibration curve. Therefore, the correlation between the two parameters mentioned above is expressed through the equation: $\mathrm{I}=0.17[\mathrm{Dox}]+1.579 ; \mathrm{R}^{2}=0.952$; dynamic range: $1-25 \mu \mathrm{g} / \mathrm{mL} ; \mathrm{RSD}=6.28 \%$. It should be mentioned that a large dynamic range was considered, but two different equations were needed in this case. Thus, for lower Dox concentration $(0.05-0.75 \mu \mathrm{g} / \mathrm{mL})$ the equation is: $\mathrm{I}=0.62$ [Dox] $-0.08 ; \mathrm{R}^{2}=0.983$; $\mathrm{LOD}=16 \mathrm{ng} / \mathrm{mL} ; \mathrm{RSD}=4.26 \%$. Commercially available screen-printed electrodes based on graphite modified with SWCNTs were also tested. Analysing the results presented in Table I, it can be concluded that the best sensitivity for Dox detection was obtained on PGE for lower concentration range, followed by Dox detection on PGE for higher concentration range, while for Dox detection on SWCNT modified SPE the sensitivity was poor. It should be mentioned that minimum three tests were done for each concentration and, in case of PGE, all the concentrations were tested on minimum three different PGE.

Table I

Analytical parameters of the electrochemical technique developed, using PGE and SWCNT modified SPE as working electrodes

\begin{tabular}{ccc}
\hline Analytical parameter & PGE & SWCNT modified SPE \\
\hline LOD & $16 \mathrm{ng} / \mathrm{mL}$ & $1 \mu \mathrm{g} / \mathrm{mL}$ \\
\hline Sensitivity & $0.62(\mu \mathrm{A} \mathrm{x} \mathrm{mL}) / \mu \mathrm{g}$ for lower concentration range & \multirow{2}{*}{$0.02(\mu \mathrm{A} \times \mathrm{mL}) / \mu \mathrm{g}$} \\
\hline RSD intra-assay & $0.17(\mu \mathrm{A} \mathrm{x} \mathrm{mL}) / \mu \mathrm{g}$ for higher concentration range & - \\
\hline RSD inter-assay (precision) & $2.29 \%(5$ tests) & $3.64 \%(3$ tests $)$ \\
\hline $\begin{array}{c}\text { RSD between consecutive tests on the same } \\
\text { PGE (Electrode surface regeneration) }\end{array}$ & $5.71 \%(3$ tests $)$ & - \\
\hline
\end{tabular}

Considering these results and the costs differences between the two types of electrodes (SWCNT modified SPE and PGE), Dox encapsulation and release, electrochemical tests were done on PGE.

Intra-assay stability was determined for PGE, thus the same concentration was tested minimum 5 times on the same PGE, while for inter-assay stability tests three different PGE were tested in the same condition. The RSD values for the intra- and inter-assay are $2.29 \%$ and $5.71 \%$, respectively as presented in Table I. In the same time, minimum 3 successive tests were done on the same electrode with just washing between testing, to prove the regeneration of the electrode surface as well as the absence of adsorption phenomenon on the surface. The RSD of $6.30 \%$ obtained from the results collected after consecutive tests performed on the same Dox solution and with the same PGE, suggested a successful regeneration of the electrode surface, after washing it with Milli-Q water and dry it.
There are several studies in which is presented the development of an electrochemical sensor for Dox, situations in which it is necessary to carry out interference studies, especially when the purpose is to determine Dox from biological samples (blood, urine, tissue). Usually glucose, ascorbic acid, uric acid and cysteine amino acid have been tested as possible interferences $[10,11,26]$. The present study aims to optimize an electrochemical method for rapid, simple and low cost testing of the encapsulation of Dox and its release process in the early development stages of a new formulation, when simple and basic release media like buffer solutions are used and there are no interferences. However, some tests were done in the same conditions for gemcitabine, another anti-tumour drug, and simvastatin, which is a statin drug used for lowering the blood lipids levels and it was proved to potentiate the anti-tumour activity of Dox 
$[4,31]$. Any analytical signal was observed by using the described electroanalytical method, for both drugs mentioned before.

The analytical parameters for the spectrophotometric detection of Dox

According to the monograph of doxorubicin hydrochloride from the European Pharmacopoeia $9^{\text {th }}$ edition from 2019 (9.8), the recommended method for Dox quantification is HPLC-UV-Vis [9]. Therefore, UVVis spectrophotometry tests were performed to check the results obtained by the optimized electrochemical procedure proposed in this study. The maximum absorption wavelength was experimentally determined from UV-Vis spectra recorded in all solvents used and for all $\mathrm{pH}$ values (data not shown).

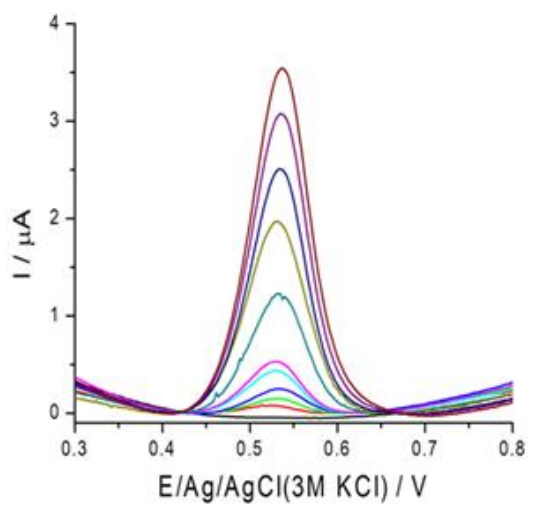

Figure 2.

DPVs of different concentrations of Dox in $0.1 \mathrm{M}$ acetate buffer solution of $\mathrm{pH} 4.5$ on PGE

Evaluation of the encapsulation process

The encapsulation of MCPs was achieved with Dox solutions of known concentration prepared in buffer solutions of different $\mathrm{pH}$, as well as from Dox solutions prepared in DMSO. This solvent was used because of the low solubility of Dox in aqueous solutions of less acid or basic $\mathrm{pH}$, as a consequence of the substitution of Dox molecules from its hydrochloride salt. As it can be seen in Table II, the results showed that EE (\%) and LC (\%) are improved when using DMSO as solvent of the feeding solution. Therefore, different concentrations of Dox in DMSO were further studied as feeding solutions and the results are also presented in Table II. Even though the EE, representing the percent of drug encapsulated or adsorbed at the surface of the MCPs from the initial quantity of the solution, is similar in all cases, the LC, representing the quantity of Dox from $100 \mathrm{mg}$ of MCPs, has higher values when more concentrated Dox solutions were used as feeding solutions. Thus, in the next studies the encapsulation of the anti-tumour drug in MCPs was performed from $10 \mathrm{mg} / \mathrm{mL}$ Dox solution prepared in DMSO. The encapsulation tests of Dox from buffer solutions of different $\mathrm{pH}$ were followed using the electrochemical optimized method, as well as through UV-Vis spectrophotometry. In Table II it can be observed that in the case of the encapsulation from Dox solution prepared in buffer solution of $\mathrm{pH} 4.5$, LC values obtained by UV-Vis spectrophotometry procedure and by electrochemical method were very similar.

The optimized electrochemical method could not be applied for the detection and quantification of Dox from the loading solution prepared in DMSO since the surface of PGE seems to be degraded by this solvent and no oxidation peak for Dox was observed when using CV or DPV. Thus, the control of the encapsulation in this particular case was done only by UV-Vis spectrophotometry.

Table II

EE and LC of Dox in the MCPs from different feeding solutions, calculated after UV-Vis or electrochemical Dox detection

\begin{tabular}{cccc}
\hline Feeding solution & Method for Dox quantification & EE (\%) & LC (\%) \\
\hline \multirow{2}{*}{$2 \mathrm{mg} / \mathrm{mL}$ Dox in 0.1 AB $(\mathrm{pH} 4.5)$} & UV-Vis tests & 21.0 & 0.07 \\
\cline { 2 - 4 } & DPV tests & 43.0 & 0.08 \\
\hline $2 \mathrm{mg} / \mathrm{mL}$ Dox in DMSO & UV-Vis tests & 37.3 & 0.35 \\
\hline $5 \mathrm{mg} / \mathrm{mL}$ Dox in DMSO & UV-Vis tests & 32.6 & 0.75 \\
\hline $10 \mathrm{mg} / \mathrm{mL}$ Dox in DMSO & UV-Vis tests & 32.4 & 2.10 \\
\hline
\end{tabular}

FT-IR study of the encapsulation process

FT-IR analysis was used to better understand the characteristics of the intermolecular interactions between different components of the MCPs and the drug, after its encapsulation. Figure 3(A) depicts the FT-IR spectra of: MCPs (black), Dox (red), MCPs-Dox after encapsulation from solution of $10 \mathrm{mg} / \mathrm{mL}$ prepared in DMSO (blue). The spectra of MCPs (Figure 3(A); black) present some characteristic bands of all three components: BSA, Chi and HA used for their synthesis. Therefore, the peaks from $1646 \mathrm{~cm}^{-1}$ and $3273 \mathrm{~cm}^{-1}$ could be attributed to amide $\mathrm{I}-\mathrm{C}=\mathrm{O}$ stretching and
-N-H stretching vibration that can be observed in the FT-IR spectra of BSA [3, 20], the peak from $1528 \mathrm{~cm}^{-1}$ correspond to amide II $-\mathrm{NH}_{2}$ bending that can be observed in the FT-IR spectra of Chi $[14,15$, 25], while peaks from $2881 \mathrm{~cm}^{-1}$ and $2941 \mathrm{~cm}^{-1}$ can be correlated with the vibration bands of $\mathrm{C}-\mathrm{H}$ bonds, characteristic for both HA and Chi [8, 20]. The strong interaction between chitosan, hyaluronic acid and BSA in MCPs lead to a new peak at $1397 \mathrm{~cm}^{-1}$ that can be attributed to $-\mathrm{C}-\mathrm{H}$ bending, information that has been already reported [25]. Hydrogen bonds and electrostatic crosslinking interactions among the 
functional groups of these components are also involved in the formation of MCPs, as it is evidenced by the shift of the corresponding peaks due to -OH stretching from $3285 \mathrm{~cm}^{-1}$ for chitosan and $3300 \mathrm{~cm}^{-1}$ for hyaluronic acid to $3273 \mathrm{~cm}^{-1}$ and those due to $-\mathrm{C}=\mathrm{O}$ stretching from $1687 \mathrm{~cm}^{-1}$ for chitosan and $1699 \mathrm{~cm}^{-1}$ for hyaluronic acid to $1646 \mathrm{~cm}^{-1}$ [15], where is probably overlapped by the amide II specific bands of BSA, especially the stretching vibration band of the $\mathrm{C}=\mathrm{O}$ bond at $1646 \mathrm{~cm}^{-1}$ that can be observed in FT-IR spectra of MCPs, confirming the BSA core formation [20].

The FT-IR specific peaks of Dox, meaning the peak from $3321 \mathrm{~cm}^{-1}$ attributed to -O-H vibration, the peak from $2905 \mathrm{~cm}^{-1}$ related with the $-\mathrm{C}-\mathrm{H}$ vibration, the peak from $1623 \mathrm{~cm}^{-1}$ generated by $-\mathrm{NH}_{2}$ vibration, as well as the strong peak of cyclic ether observed at $1017 \mathrm{~cm}^{-1}$ can be observed in the spectra presented in Figure 3(A); (red).

As it can be observed and according to the literature data $[5,20]$, the specific bands of Dox appear at wave number situated closed to the above mentioned components used for the fabrication of MCPs which justifies their overlap in the spectrum recorded for MCPs-Dox (Figure 3(A); blue). Thus, by comparison with the spectra of unloaded MCPs and of Dox, the main characteristic peaks of the MCPs-Dox could be assigned. The most important modifications observed in the FT-IR spectra of MCPs-Dox featured an obvious new peak and a strong increase of another one. Thus, the new peak observed at $1516 \mathrm{~cm}^{-1}$ can be due to a new amide bond formation which proves the conjugation between the drug and the carrier [33]. Furthermore, the strong increase of the peak from $1623 \mathrm{~cm}^{-1}$ can be related with the new amide bond formation, this being probably the result of the condensation reaction between - $\mathrm{COOH}$ group provided by hyaluronic acid from MCPs and the free amino group $-\mathrm{NH}_{2}$ from Dox, as it was already reported [20]. The infrared spectra of MCPs-Dox confirm the chemical stability of the drug in the carriers as well as the interaction between the components of the MCPs and Dox.

SEM study of the encapsulation process

SEM images of MCPs obtained before and after encapsulation of Dox using aqueous solutions of different $\mathrm{pH}$ as well as DMSO solution, are presented in Figure 3(B-D). It can be observed that the aspect and dimensions of the MCPs-Dox vary depending of the loading media: $\mathrm{pH} 4.5$ (Figure 3(C)) and DMSO (Figure 3(D)). A homogenous distribution of Dox in the MCPs can be observed in the SEM image of MCPsDox from DMSO solution (Figure 3(D)), but compared with the ones loaded from buffer solution of $\mathrm{pH} 4.5$, these present a halo which can be associated to the accumulation of Dox in the shell of the MCPs.
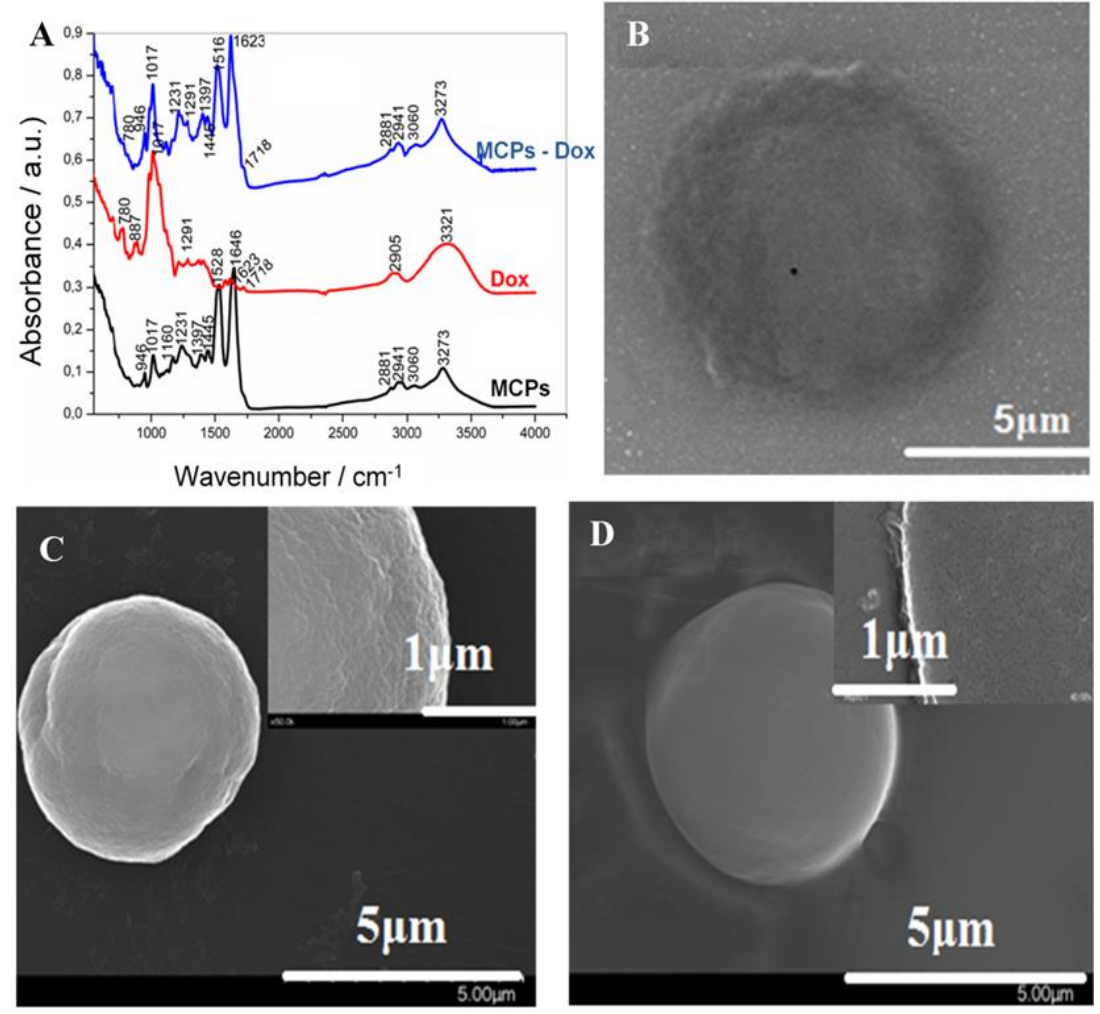

Figure 3.

(A) FTIR analysis of MCPs (black); Dox (red) and MCPs-Dox (blue). SEM images of: (B) MCPs; (C) MCPs-Dox encapsulated from $2 \mathrm{mg} / \mathrm{mL}$ Dox solution in 0.1 acetate buffer of $\mathrm{pH} 4.5$; and (D) MCPs-Dox encapsulated from $10 \mathrm{mg} / \mathrm{mL}$ Dox solution in DMSO. 
Confocal laser scanning microscopy study of the encapsulation process

CLSM images of MCPs-Dox after their loading in different experimental conditions are presented in Figure 4.

Thus, the details of each type of MCPs-Dox can be highlighted with this technique. Dox has intrinsic fluorescence which serves as a valuable tool in research and imaging, having an emission signal at $595 \mathrm{~nm}$ that can be registered upon excitation with a laser at $470 \mathrm{~nm}[6,18,27]$. It was observed that by loading the MCPs from buffer solutions of different $\mathrm{pH}$ (Figure $4(\mathrm{~A}, \mathrm{~B}, \mathrm{C}))$, Dox gets into the core of the MCPs at a higher concentration than in the case of MCPs in DMSO, where the shell of the MCPs is the preferred region by Dox molecules (Figure 4(D)), as it was supposed also from the SEM images.

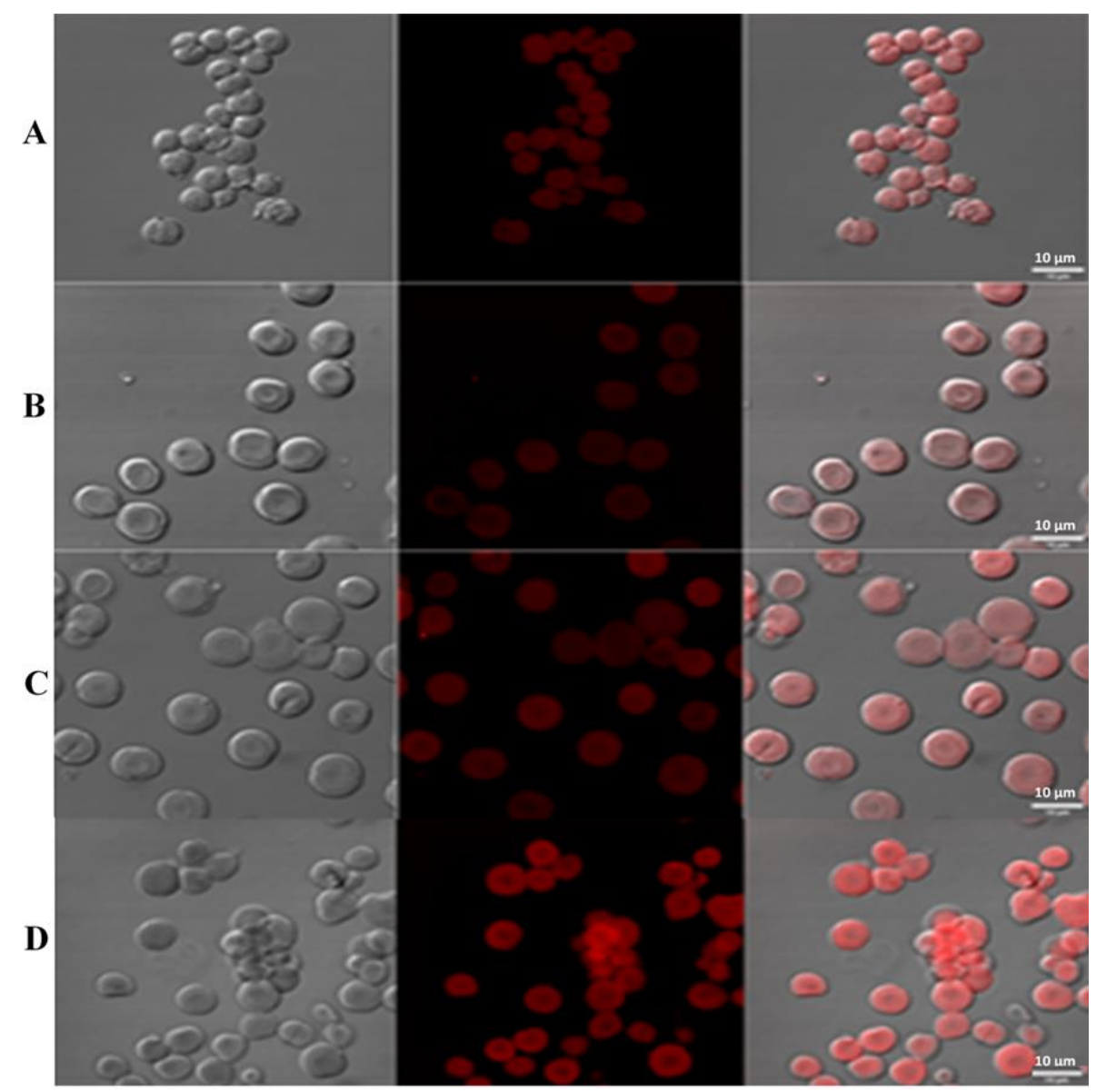

Figure 4.

Confocal laser scanning microscopy (CLSM) of MCPs-Dox encapsulated from Dox solution prepared in:

(A) acetate buffer of pH 4.5, (B) acetate buffer of pH 5, (C) acetate buffer of pH 5.5, (D) DMSO.

\section{Characterization of the release profile}

After analysing the samples resulted from the process of Dox release in buffered media of different $\mathrm{pH}$, it appears that cumulative release is better in buffer solution of $\mathrm{pH} 5$, followed by buffer solution of $\mathrm{pH}$ 4.5 , while in buffer solution of $\mathrm{pH} 6.8$ the release rate was inappropriate (Figure 5(A)). This phenomenon is probably related with the crystallization of Dox molecules observed in the SEM images at less acidic $\mathrm{pH}$. The fact that the release is better at more acidic $\mathrm{pH}$ is an advantage of using these MCPs, being known that the $\mathrm{pH}$ of the extracellular media of the tumour is more acidic than the physiological one, sometimes reaching values under $6[28,35]$. This property of the studied MCPs is an additional argument for the targeted delivery of the drug, following the affinity of HA for CD44 receptors overexpressed at the surface of tumour cells [17].

The release tests were achieved in different dynamic conditions, aliquoting $20 \mu \mathrm{L}$ from some samples and $500 \mu \mathrm{L}$ from others at each release time tested. As it can be observed in Figure 5(B), the results showed that the release profile is better in more dynamic condition, when $500 \mu \mathrm{L}$ were sampled and replaced with the same volume of pure solvent. This could be explained by the shifting of the balance towards Dox release process due to decrease of drug concentration in the release media. 

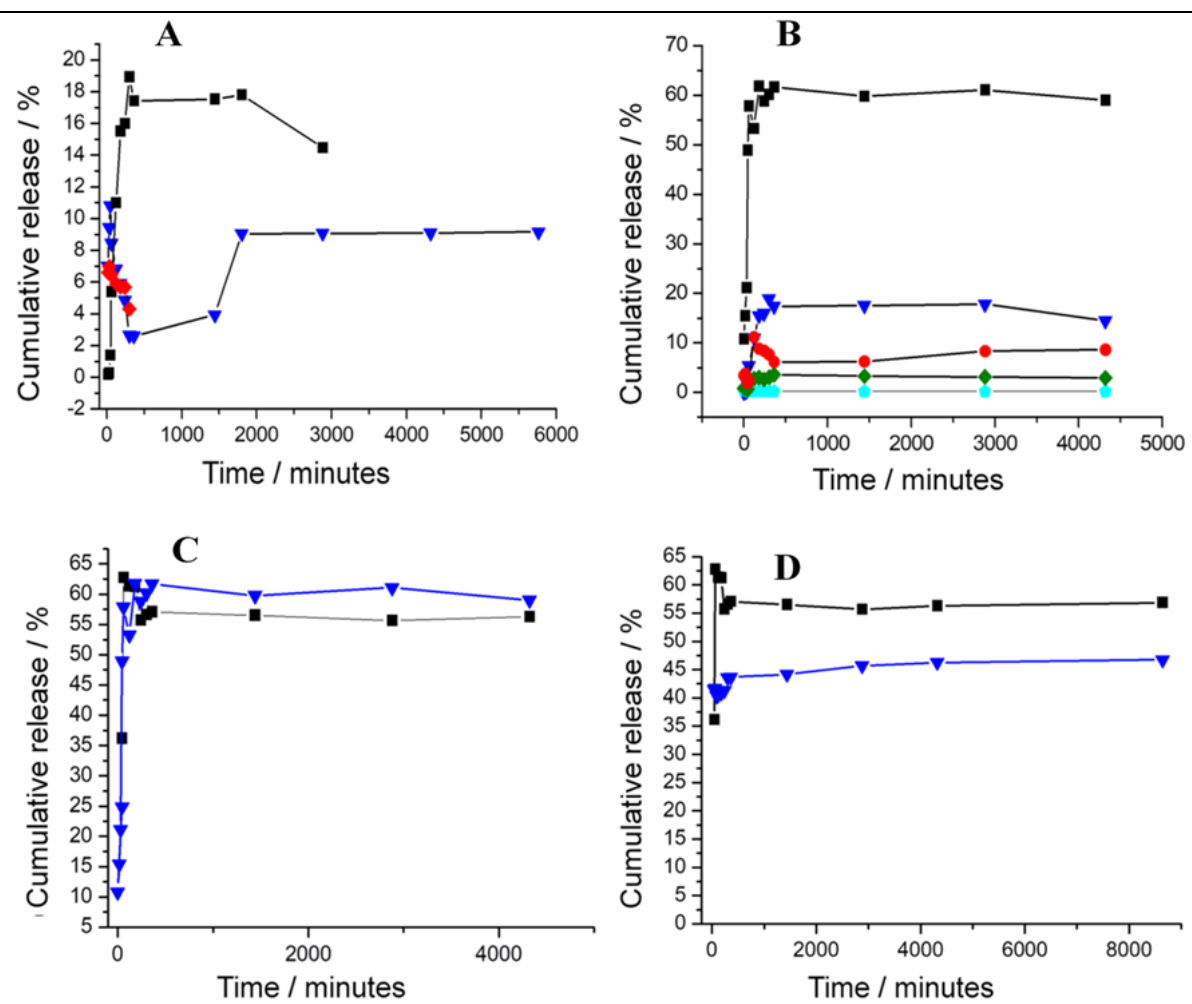

Figure 5.

(A) Cumulative release of Dox at pH 5 (black), pH 4.5 (blue) and pH 6.8 (red). (B) Cumulative release of Dox at pH 5 under different dynamic condition: with $500 \mu \mathrm{L}$ (black) and $20 \mu \mathrm{L}$ (blue, red, green and cyan) sampled from the release media at each time tested. (C) Cumulative release of Dox at $\mathrm{pH} 5$ on the first set of data (black) and on the second set of data (blue). (D) Cumulative release of Dox at pH 5 obtained with DPV (black) and UV-Vis (blue) detection.

Considering this, some tests were repeated in the best release condition and the results obtained represent the average of three independent release experiments and are presented in Figure 5(C) confirmed the previous outcomes.

UV-Vis spectrophotometry was used as control method for our optimized electrochemical DPV procedure. The comparative results in terms of cumulative release (\%) are presented in Figure 5(D). An acceptable average correlation was calculated based on the value of this parameter obtained after 6 days. The relatively small difference between the cumulative releases calculated may be due to the different sensitivity between the 2 analytical methods, this being better for the DPV technique. Also, HPLC-MS studies performed on freshly prepared and old Dox solutions respectively (data not presented), have shown that the degradation of this compound, from molecular absorption point of view, occurs without the fragmentation of the molecule, but rather via their agglomeration/crowding. This phenomenon can cause the decrease of the molecular absorption signal registered in UV-Vis without affecting the electrochemical oxidation signal followed in the DPV detection which is based on the functional groups that can suffer oxidation processes.
The experimental results obtained with the optimized electrochemical method and with UV-Vis spectrophotometry were statistically analysed using Student's t-test and the values showed a good accordance and indicated that there was no significant difference between the method performances regarding the precision, with the calculated values of $\mathrm{t}$ at $\alpha=0.05$ $\left(\mathrm{t}_{\text {calculated }}=1.525<\mathrm{t}_{\text {theoretical }}=2.132, \mathrm{p}=0.202\right)$. The test was performed on 3 random values of cumulative release (\%) obtained using each method, each value representing the average result of three individual tests.

\section{SEM study of the release process}

The SEM images of MCPs-Dox after the release process (Figure 6) confirm the results obtained by detection of Dox from the release samples. The efficient release of Dox at $\mathrm{pH} 5$ is supported by the porous dilated structure of the MCPs-Dox when immersed in this solution. At $\mathrm{pH} 4.5$, Dox crystals could be noticed in the core of the MCPs-Dox, this explaining the slower release of the substance, while at $\mathrm{pH} 6.8$ the presence of conglomerates probably made from Dox crystals can be seen at the surface of the MCPs-Dox, this sustaining the poor release of the medicine in this media observed by UV-Vis and DPV tests. 

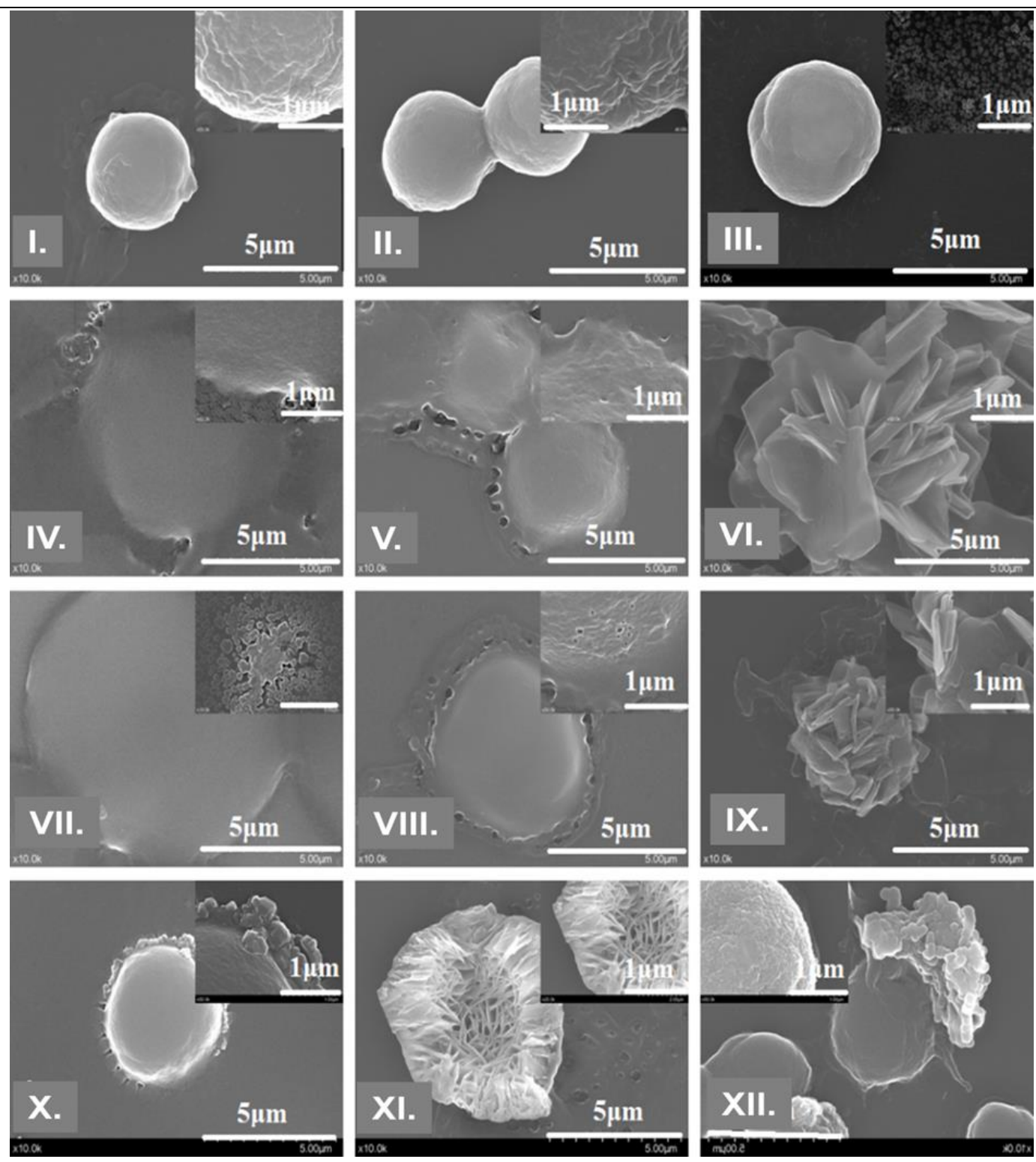

Figure 6.

SEM images of BSA/HA/Chi/HA MCPs-Dox after release in acetate buffer solution of pH 4.5 (I., IV., VII., X.), citrate buffer solution of pH 5 (II., V., VIII., XI.) and phosphate buffer solution of pH 6.8 (III., VI., IX., XII.).

\section{Conclusions}

An innovative, rapid, sensitive and low-cost electrochemical procedure was applied for the first time in this study for establishing the in vitro release profile of the Dox anti-tumour drug. The optimized electrochemical technique and UV-Vis spectroscopy were used for the quantification of Dox after encapsulation and during the release experiments. It was observed that MCPs-Dox gave better loading characteristics in DMSO compared with aqueous solutions of different $\mathrm{pH}$ and the best release profile was observed at $\mathrm{pH}$ 5. These results lead us believe that these MCPs are promising tools for targeted drug delivery systems development, being known that the tumour tissue $\mathrm{pH}$ is more acidic. The results obtained with the proposed method were confirmed by UV-Vis tests. Several techniques such as FT-IR, CLSM and SEM were successfully applied to highlight the presence of Dox in MCPs-Dox.

\section{Acknowledgement}

This work was supported by a grant of the Romanian Minister of Research and Innovation, CCCDI UEFISCDI, project number PNIII-P1-1.2-PCCDI-20170221/59PCCDI/2018 (IMPROVE), within PNCDI III. This paper was published under the frame of European Social Found, Human Capital Operational Programme 2014-2020, project no. POCU/380/6/13/125171. Iulia Rus acknowledges UMF Grant no. 1529/58/18.01.2019.

\section{Conflict of interest}

The authors declare no conflict of interest. 


\section{References}

1. Achim M, Tefas LR, Iovanov R, Vonica-Gligor AL, Barbu-Tudoran L, Tomuță I, Preparation and in vitro evaluation of felodipine loaded poly( $\varepsilon$-caprolactone) microspheres: Quality by Design approach. Farmacia, 2019; 67(4): 670-683.

2. Beijnen JH, Van der Houwen OAGJ, Underberg WJM, Aspects of the degradation kinetics of doxorubicin in aqueous solution. Int J Pharm., 1986; 32(2-3): 123-131.

3. Bouhekka A, Bürgi T, In situ ATR-IR spectroscopy study of adsorbed protein: Visible light denaturation of bovine serum albumin on $\mathrm{TiO}_{2}$. Appl Surf Sci., 2012; 261: 369-374.

4. Buranrat B, Suwannaloet W, Naowaboot J, Simvastatin potentiates doxorubicin activity against MCF-7 breast cancer cells. Oncol Lett., 2017; 14(5): 6243-6250.

5. Butt AM, Amin MCIM, Katas H, Sarisuta N, Witoonsaridsilp $\mathrm{W}$, Benjakul $\mathrm{R}$, In vitro characterization of pluronic F127 and D- $\alpha$-tocopheryl polyethylene glycol 1000 succinate mixed micelles as nanocarriers for targeted anticancer-drug delivery. J Nanomater., 2012; 2012: 916573: 1-11.

6. Chen NT, Wu CY, Chung CY, Hwu Y, Cheng SH, Mou CY, Probing the Dynamics of DoxorubicinDNA Intercalation during the Initial Activation of Apoptosis by Fluorescence Lifetime Imaging Microscopy (FLIM). PLoS One, 2012; 7(9): e44947: 1-8.

7. Drăgoi CM, Nicolae AC, Dumitrescu IB, Popa DE, Ritivoiu M, Arsene AL, DNA targeting as a molecular mechanism underlying endogenous indoles biological effects. Farmacia, 2019; 67(2): 367-377.

8. El-kharrag R, Abdel Halim SS, Amin A, Greish YE, Synthesis and characterization of chitosan-coated magnetite nanoparticles using a modified wet method for drug delivery applications. Int J Polym Mater Polym Biomater., 2019; 68(1-3): 73-82.

9. European Pharmacopoeia Online 9.8, http://online6. edqm.eu/ep908.

10. Hahn Y, Lee HY, Electrochemical Behavior and Square Wave Voltammetric Determination of Doxorubicin Hydrochloride. Arch Pharm Res., 2004; 27(1): 31-34.

11. Hajian R, Tayebi Z, Shams N, Fabrication of an electrochemical sensor for determination of doxorubicin in human plasma and its interaction with DNA. $J$ Pharm Anal., 2017; 7(1): 27-33.

12. Hashemzadeh N, Hasanzadeh M, Shadjou N, EivaziZiaei J, Khoubnasabjafari M, Jouyban A, Graphene quantum dot modified glassy carbon electrode for the determination of doxorubicin hydrochloride in human plasma. J Pharm Anal., 2016; 6(4): 235-241.

13. Janssen MJH, Crommelin DJA, Storm G, Hulshoff A, Doxorubicin decomposition on storage. Effect of $\mathrm{pH}$, type of buffer and liposome encapsulation. Int J Pharm., 1985; 23(1): 1-11.

14. Jayakumar R, Prabaharan M, Nair SV, Tamura H, Novel chitin and chitosan nanofibers in biomedical applications. Biotechnol Adv., 2010; 28(1): 142-150.

15. Krishna AS, Radhakumary C, Sreenivasan K, Calcium ion modulates protein release from chitosan-hyaluronic acid poly electrolyte gel. Polym Eng Sci., 2015; 55(9): 2089-2097.
16. Leng Q, Mixson AJ, The neuropilin-1 receptor mediates enhanced tumor delivery of $\mathrm{H}_{2} \mathrm{~K}$ polyplexes. J Gene Med., 2016; 18(7): 134-144.

17. Li SD, Howell SB, CD44-targeted microparticles for delivery of cisplatin to peritoneal metastases. Mol Pharm., 2010; 7(1): 280-290.

18. Motlagh NSH, Parvin P, Ghasemi F, Atyabi F, Fluorescence properties of several chemotherapy drugs: doxorubicin, paclitaxel and bleomycin. Biomed Opt Express, 2016; 7(6): 2400-2406.

19. National Center for Biotechnology Information, PubChem Database. Doxorubicin, https://pubchem.ncbi. nlm.nih.gov/compound/Doxorubicin.

20. Paşcalău V, Pall E, Tertis M, Suciu M, Cristea C, Borodi G, Bodoki A, Topală T, Stiufiuc R, Moldovan A, Pavel C, Marinca T, Popa C, In vitro study of BSA gel/polyelectrolite complexes core shell microcapsules encapsulating doxorubicin for antitumoral targeted treatment. Int J Polym Mater Polym Biomater., 2019; 68(1-3): 60-72.

21. Paşcalău V, Tertis M, Pall E, Suciu M, Marinca T, Pustan M, Merie V, Rus I, Moldovan C, Topala T, Pavel C, Bovine serum albumin gel/polyelectrolyte complex of hyaluronic acid and chitosan based microcarriers for Sorafenib targeted delivery. $J$ Appl Polym Sci., 2020; 137: 49002: 1-16.

22. Peng Z, Li S, Han X, Al-Youbi AO, Bashammakh AS, El-Shahawi MS, Leblanc RM, Determination of the composition, encapsulation efficiency and loading capacity in protein drug delivery systems using circular dichroism spectroscopy. Anal Chim Acta, 2016; 937: 113-118.

23. Peniche C, Fernández M, Rodríguez G, Parra J, Jimenez J, Bravo AL, Gómez D, San Román J, Cell supports of chitosan/hyaluronic acid and chondroitin sulphate systems. Morphology and biological behaviour. J Mater Sci Mater Med., 2007; 18(9): 1719-1726.

24. Pillai G, Nanotechnology toward Treating Cancer. In: Applications of Targeted Nano Drugs and Delivery Systems, $1^{\text {st }}$ ed.; Shyam M, Shivendu R, Nandita D, Raghvendra K, Sabu T, Eds.; Elsevier Inc.: Amsterdam, Netherlands, 2019; 221-256.

25. Radhakumary C, Antonty M, Sreenivasan K, Drug loaded thermoresponsive and cytocompatible chitosan based hydrogel as a potential wound dressing. Carbohydr Polym., 2011; 83(2): 705-713.

26. Rahimi M, Bagheri Gh A, Fatemi SJ, A new sensor consisting of bird nest-like nanostructured nickel cobaltite as the sensing element for electrochemical determination of doxorubicin. J Electroanal Chem., 2019; 848: 113333: 1-8.

27. Shah S, Chandra A, Kaur A, Sabnis N, Lacko A, Gryczynski Z, Fudala R, Gryczynski I, Fluorescence properties of doxorubicin in PBS buffer and PVA films. J Photochem Photobiol B., 2017; 170: 65-69.

28. Thews O, Riemann A, Tumor $\mathrm{pH}$ and metastasis: a malignant process beyond hypoxia. Cancer Metastasis Rev., 2019; 38(1-2): 113-129.

29. Vassilev P, Koper MTM, Electrochemical reduction of oxygen on gold surfaces: A density functional theory study of intermediates and reaction paths. $J$ Phys Chem C., 2007; 111(6): 2607-2613. 
30. Volodkin DV, Larionova NI, Sukhorukov GB, Protein encapsulation via porous $\mathrm{CaCO}_{3}$ microparticles templating. Biomacromolecules, 2004; 5(5): 1962-1972.

31. Werner M, Atil B, Sieczkowski E, Chiba P, Hohenegger M, Simvastatin-induced compartmentalisation of doxorubicin sharpens up nuclear topoisomerase II inhibition in human rhabdomyosarcoma cells. Naunyn Schmiedebergs Arch Pharmacol., 2013; 386(7): 605-617.

32. Wuang SC, Neoh KG, Kang ET, Leckband DE, Pack DW, Acid-Sensitive Magnetic Nanoparticles as Potential Drug Depots. AIChE J., 2011; 57(6): $1638-1645$

33. Xie CX, Tian TC, Yu ST, Li L, pH-sensitive hydrogel based on carboxymethyl chitosan/sodium alginate and its application for drug delivery. J Appl Polym Sci., 2019; 136(1): 46911: 1-6.

34. Yu MK, Jeong YY, Park J, Park S, Kim JW, Min JJ, Kim K, Jon S, Drug-loaded superparamagnetic iron oxide nanoparticles for combined cancer imaging and therapy in vivo. Angew Chem Int Ed Engl., 2008; 47(29): 5362-5365.

35. Zhang H, Liu XL, Zhang YF, Gao F, Li GL, He Y, Peng ML, Fan HM, Magnetic nanoparticles based cancer therapy: current status and applications. Sci China Life Sci., 2018; 61(4): 400-414.

36. Zhao N, Woodle MC, Mixson AJ, Advances in Delivery Systems for Doxorubicin. J Nanomed Nanotechnol., 2018; 9(5): 519: 1-9. 